\title{
Research of Load and Structural Direct Calculation on Flat-Type River-Sea-Going Ship
}

\author{
Zhiyong Pei ${ }^{1,2}$, Zhihui Zhu ${ }^{2}$ and Weiguo $\mathrm{Wu}^{1,2}$ \\ 1. Key Laboratory of High Performance Ship Technology of Ministry of Education, Wuhan 430064, Hubei, China \\ 2. Department of Naval Architecture, Ocean and Structural Engineering, School of Transportation, Wuhan University of Technology, \\ Wuhan 430064, Hubei, China
}

\begin{abstract}
River-sea-going ship is popular because it can directly transport from river to sea, reducing the cargo transfer process, eliminating the loss of goods and shortening the voyage time so that the shipping cost can be decreased and transport efficiency can be improved. To increase its capacity and to obtain better economy, the present river-sea-going ship is usually designed with large ratio of breadth to depth which exceeds the definition of existing rules. The characteristic of wave load is also quite different from that on sea-going ship or inland ship. In the present research, the exceeding probability level of wave load is studied firstly according to the actual status of navigation route. Long-term prediction on wave load is performed based on selected wave spectrum, wave scatter diagram and exceeding probability level. The equivalent design wave height can be obtained, and then the wave load can be calculated. Furthermore, the loads are transferred to entire structural model and the finite element analysis is performed. The structural yield strength and buckling strength are evaluated.
\end{abstract}

Key words: Flat-type river-sea-going ship, load direct calculation, structural direct calculation, exceeding probability level of wave load, buckling, strength assessment.

\section{Introduction}

In 2013, total transportation volume in Yangtze River reaches $1,920,000,000 \mathrm{t}$, ranking the first of world's inland transportation volume for nine consecutive years [1]. More than $40 \%$ economic outputs of China generate in the valley of Yangtze River. With the rapid economic development, Wuhan Newport, locating at the middle of Yangtze River and playing an important role on economic of the valley of Yangtze River, regards "transporting hundred million tonnages cargoes, 10 million TEUs (twenty-feet equivalent units)" as its goal. Its strategy is to build the biggest international inland port which combines series of advanced port technologies together. To achieve this strategy, Wuhan organizes TEU transport in many ways and becomes the container transport

Corresponding author: Zhiyong Pei, Dr., associate professor, research fields: ultimate strength of structure, structural optimization design, buckling/plastic analysis and hydro-elastoplasticity. E-mail: zhiyong_pei@whut.edu.cn. centre in the central region of China. The river-sea-going container ship with large capacity navigating between Wuhan Newport and Shanghai Yangshan Port or Lingbo Beilun Port is demanded by shipping market.

It is noted that river-sea-going ship is capable of transporting directly from river to sea so that the cargo transfer process is reduced, while the loss of goods, as well as the voyage time, can be shortened. The shipping cost can be decreased and transport efficiency would be improved in such way. So, it is popular for ship owners due to its economic and social benefits. As early as 1920s, the rudiment of river-sea-going transport was appeared between river and shelter sea region in Europe. The inland ship with good performance and/or small sea-going ship are adopted for river-sea-going transport [2]. Since the 1950s, the river-sea-going transport was organized by the former Soviet Union. The river-sea-going multiple purpose ship "Do Rove Engineer" can withstand the 
storm of Level 8. Comparison with the barges in the same route, the productivity can be improved 4.1 times. It was further developed after 1970s. The series of 2,000-DWT (dead weight tonnage) multiple purpose ship "Yakutsk", which could carry container, dry cargo and bulk, had become an independent river-sea-going ship type [3]. It is reported that annual growth of river-sea-going transport was about $20 \%$ in the European Union countries [4]. Recently, the research focuses on the application of energy saving technology and the development of high efficiency loading/unloading ship with large hatch opening [5].

The reasonableness of river-sea-going transport was demonstrated and discussed in the 1950s by Chinese researchers. The 5,000-DWT oil tanker was designed to navigate from Hunan Changling to Dalian and Japan in the early of 1970s, and 5,000-DWT bulk carrier was succeeded in carrying coal from Qinhuangdao directly to Wuhan in the middle of 1970s [6]. After that, the river-sea-going transport was developed rapidly and made remarkable achievements in China due to its advantages, such as high efficiency, low consumption and low cost. The deadweight of river-sea-going ship can reach 5,000 DWT, 8,000 DWT, or even 10,000 DWT from original 500 DWT and 800 DWT [7]. In general, the existing river-sea-going ships were small-capacity, aging, high-energy-consumption, low-efficiency and poor-economic-characteristics so that they could not better adapt to the development of economy and modern society, as well as the construction of the "Yangtze River Golden Waterway". In view of this, the authors devote themselves to develop new river-sea-going container ship to overcome the existing deficiencies.

In accordance with our investigation results, ships with larger capacity usually have merit in the current shipping market, because the cost of fuel oil accounts for more than half of the total cost. However, the Yangtze River is natural channel and the channel depth is shallow so that the draft is limited. The depth is also constrained due to the bridge clearance height. The ship length is restricted by the demand of flexible maneuverability in inland river. The most effective way to get larger capacity for cargoes is to increase ship breadth. With the increase of ship breadth, the ratio of $B / D$ (breadth to depth) may be larger than that defined in the present rules so that there are difficulties on wave load calculation and rational structural design. The load direct calculation and structural direct calculation are necessary in order to ensure the safety of designed ship structure.

In the present study, a river-sea-going container ship with the ratio of breadth to depth 2.98 is regarded as objective. At first, exceeding probability level of wave load is set in accordance with the actual status of navigation route and actual operating experience. Successively, wave parameters representing the characters of specified navigation route are imported to SESAM software. The loads acting on the ship structure are calculated using WADAM solver. Then, structural direct calculation is conducted, and the stress distribution of each component is obtained. Finally, the structural yield strength and buckling strength are evaluated.

\section{Key Technologies of River-Sea-Going Container Ship in Yangtze River}

\subsection{Status of River-Sea-Going Ship in Yangtze River}

The ship navigating in Yangtze River is required shallow draft and flexible maneuverability. The sea-going ship is charactered by good structural strength and sea-keeping performance. The river-sea-going ship navigates in both Yangtze River and sea so that it shall satisfy shallow draft, flexible maneuverability, sufficient structural strength and excellent sea-keeping performance simultaneously. The existing river-sea-going ship usually has small capacity for cargoes and designed in accordance with rules for sea-going ship. Hydrometeorological condition of navigation route is not considered thoroughly. As a result, the light weight is heavy, and 
it lacks the performance advantage of neither inland ship nor sea-going ship. The demand of high performance river-sea-going ship with large capacity becomes more and stronger with the improvement of the Yangtze River's channel and the port handling capacity. The present ship cannot satisfy such requirement. Furthermore, the present situation, such as aging and lacking energy saving device, is far from the requirement of "low-carbon society" and the construction of "Yangtze River Golden Waterway" which severely restricts the development of the shipping industry [7].

\subsection{Key Technologies of River-Sea-Going Container Ship}

The authors have designed a new river-sea-going container ship with characteristics of larger capacity, lighter structural weight, lower fuel consumption and less emission by performing economic analysis, seaworthy performance research and structural safety performance research. The theoretical analysis, numerical simulation and model test are combined together to solve key technical problems in safety technology, energy-saving technology and green ship technology as follows:

- bow slamming;

- maneuverability in shallow channel;

- lightweight structural design;

- cooperating with present channel and port situation;

- application of energy saving technology.

Considering the requirement of large capacity, the present conditions of channel and port, as well as the result of economic analysis, the main principles of design ship are adopted as: overall length of $136.5 \mathrm{~m}$, breadth of $25.6 \mathrm{~m}$, depth of $8.6 \mathrm{~m}$, design draft of $5.5 \mathrm{~m}$ (structural draft of $6.3 \mathrm{~m}$ ), as shown in Table 1 . Double bottom (1.5-m height) and double hull (2.6-m width) structures are adopted. There are two layers stringers in the double hull from baseline $3.8 \mathrm{~m}$ and $6.3 \mathrm{~m}$. The typical cross section is shown in Fig. 1 .
Table 1 Main principles of river-sea-going container ship.

\begin{tabular}{ll}
\hline Parameters & Value \\
\hline Overall length $L_{O A}(\mathrm{~m})$ & 136.50 \\
Length between perpendicular $L_{P P}(\mathrm{~m})$ & 130.00 \\
$B$ (breadth) $(\mathrm{m})$ & 25.60 \\
$D$ (depth) $(\mathrm{m})$ & 8.60 \\
Design draft (structural draft) $d / d_{s}(\mathrm{~m})$ & $5.50(6.30)$ \\
Breadth of hatch $b(\mathrm{~m})$ & 20.40 \\
Ratio of $B / D$ (breadth to depth) & 2.98 \\
Ratio of hatch $b / B$ (breadth to breadth) & 0.797 \\
\hline
\end{tabular}

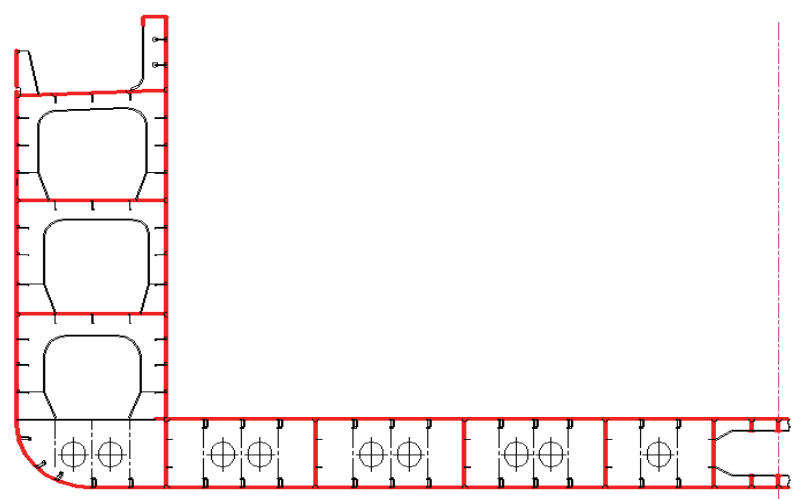

Fig. 1 Typical cross section.

The ratio of $B / D$ is 2.98 , which is larger than 2.5 defined by present rules published by Chinese Classification Society. The present rule formula on wave load can not be available any more. Load direct calculation has to be conducted. The ratio of hatch $b / B$ (breadth to breadth) reaches 0.797 . It is necessary to conduct structural direct calculation to validate the strength under combined bending and torsional moments.

\section{Load Direct Calculation}

The navigation route for river-sea-going ship includes inland river and sea part. Hydrostatic load is dominant and wave load is relative small in inland river part whereas the wave load shall be much larger than hydrostatic load in the sea part. So, the wave load subjected to river-sea-going ship has the intermittent character in all life cycles which is quite different from that for inland ship and/or sea-going ship. The traditional wave load formula defined in the rules for inland ship and sea-going ship [8] is not proper for 
river-sea-going ship. Furthermore, the ratio of $B / D$ reaches 2.98 so that load and structural direct calculations have to be performed to determine the structural size.

In this chapter, the exceeding probability level of wave load is researched. Long-term prediction on wave load is conducted based on wave spectrum, wave scatter diagram and reasonable exceeding probability level. The amplitude of equivalent design wave can be calculated. Finally, the wave load can be obtained in accordance with equivalent design wave theory.

\subsection{Exceeding Probability Level of Wave Load}

The most of time for river-sea-going ship between Wuhan Newport and Shanghai Yangshan or Ningbo Beilun Port is navigating in inland river, and it is relative short time in the sea. The exceeding probability level of wave load shall reflect the characteristics of specified route and actual operating properly. The exceeding probability level, namely the probability exceeding the long term prediction, is related to the wave cycles in ship's life period. So, it is necessary to determine the subjected wave cycles before decide the exceeding probability level of long-term prediction. In fact, the exceeding probability level of long term prediction is the reciprocal of the number of wave cycles [9].

The design life of river-sea-going ship is set as 25 years, totally $7.884 \times 10^{8} \mathrm{~s}$. According to the investigation result, the average voyage rate is $75 \%$ so that the voyage time shall be $5.913 \times 10^{8} \mathrm{~s}$ during all life cycle. For the river-sea-going ship navigating from Wuhan Newport to Shanghai Yangshan or Ningbo Beilun Port, there is less than $20 \%$ in the sea part (E1 navigation area). Considering the period distribution to over zero in the wave scatter diagram of E1 navigation area, the number of wave cycles during all life period shall be $18,780,000$. The corresponding exceeding probability level of long term prediction is $10^{-7.28}$. To ensure the safety of navigating ship, the strength reservation is taken into account and the exceeding probability level is set as $10^{-7.3}$.

\subsection{Selection of Wave Spectrum}

Wave spectrum reflects the characteristics of wave energy distribution in a specified navigation area. For statistical wave load prediction, the best way to estimate ship's response is to use measured wave spectrum representing actual wave situation. Although Chinese researchers have proposed many wave spectrums for Chinese coastal navigation area, their application are not well validated and recognized. In such case, load direct calculation has to be conducted using international famous wave spectrums, such as the Pierson-Moskowitz spectrum (referred as P-M spectrum), ISSC two-parameters spectrum and JONSWAP spectrum [10].

$\mathrm{P}-\mathrm{M}$ spectrum is obtained by fitting observed fully-developed waves so that it is suitable for the fully-developed waves. ISSC two-parameter spectrum applies to not only the fully-developed waves but also the growing waves and/or waves generated by ground swell. The JONSWAP spectrum is proposed by observing the waves in finite wind district performed by Joint North Sea Wave Project. It is suitable for the waves in growing status. The design ship navigates in E1 navigation area of East China Sea which represents the growing waves in finite wind zone. The JONSWAP spectrum is adopted which is more appropriate, especially for coastal or shelter area.

\subsection{Wave Scatter Diagram}

Wave scatter diagram, consisting of different wave conditions and the occurrence probability of every wave conditions, represents the environmental condition of navigation area. The sea part of navigation route belongs to E1 navigation area of East China Sea. The corresponding wave scatter diagram [11] is shown in Table 2. 
Table 2 Wave scatter diagram of E1 navigation area.

\begin{tabular}{|c|c|c|c|c|c|c|c|c|c|c|c|c|}
\hline \multirow{2}{*}{ Related parameters } & & \multicolumn{11}{|c|}{ Total } \\
\hline & & 7 & 97 & 274 & 311 & 197 & 82 & 25 & 6 & 1 & + & 1,000 \\
\hline \multirow{13}{*}{ Significant wave height (m) } & $>9$ & & & & & & & & + & + & + & + \\
\hline & $7.5 \sim 9$ & & & & & & + & + & + & + & & 1 \\
\hline & $6 \sim 7.5$ & & & & & + & 1 & 2 & 1 & + & & 4 \\
\hline & $5 \sim 6$ & & & & + & 2 & 4 & 2 & 1 & + & & 10 \\
\hline & $4 \sim 5$ & & & + & 3 & 10 & 9 & 3 & 1 & & & 26 \\
\hline & $3.25 \sim 4$ & & & 2 & 12 & 19 & 10 & 3 & + & & & 46 \\
\hline & $2.5 \sim 3.25$ & & 1 & 12 & 32 & 30 & 14 & 4 & 1 & + & & 95 \\
\hline & $1.85 \sim 2.5$ & & 5 & 33 & 56 & 39 & 15 & 4 & 1 & + & & 152 \\
\hline & $1.25 \sim 1.85$ & + & 16 & 65 & 78 & 42 & 14 & 3 & 1 & + & & 219 \\
\hline & $0.85 \sim 1.25$ & 1 & 23 & 63 & 58 & 26 & 8 & 2 & + & & & 181 \\
\hline & $0.5 \sim 0.85$ & 2 & 27 & 57 & 44 & 18 & 5 & 1 & + & & & 155 \\
\hline & $0.1 \sim 0.5$ & 3 & 25 & 40 & 26 & 10 & 3 & 1 & + & & & 108 \\
\hline & $0 \sim 0.1$ & + & 1 & 1 & 1 & + & & & & & & 3 \\
\hline \multicolumn{2}{|c|}{ Average zero-crossing period (s) } & $<3.5$ & 4 & 5 & 6 & 7 & 8 & 9 & 10 & 11 & 12 & Total \\
\hline
\end{tabular}

"+" represents its value larger than 0.1 but less than 0.5 .

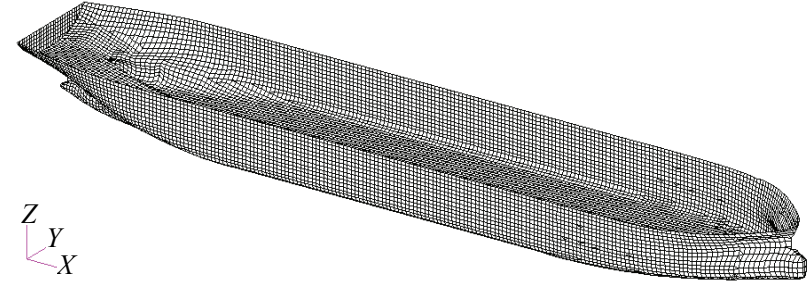

Fig. 2 Load calculation model.

\subsection{Load Calculation}

When load calculation is conducted, the ship hull is always regarded as rigid body. Outer shell model is adopted for achieving external pressure distribution and entire ship model including all components is used to obtain mass distribution. Under the specified wave parameters, the external pressure distribution along ship hull surface and corresponding acceleration at the gravity centre can be gotten. The inertial force, multiplying mass by acceleration, is treated as external load by employing D'Alembert's principle. The inertial force and external pressure are combined together as external load subjected to structural model.

\subsubsection{Load Calculation Model}

Outer shell model is enough for load calculation because the influence of deflection is not considered. To eliminate the load transferring error, the load calculation model shall be as consistent as possible with the outer shell of structural calculation model. The hydrostatic pressure is available for the elements below still water surface only. Hydrodynamic pressures below and above still water surface are estimated based on the linear calculations. The same pressure value is assigned to a point on the hull surface above still water surface as the value at the still water surface right below the point. The hydrostatic pressure and hydrodynamic pressure are combined as the total pressure. If the total pressure is calculated negative, it is truncated zero. The load calculation model is shown in Fig. 2.

\subsubsection{Mass Model}

As is well known, mass distribution shall influence the floating situation and thus influence the pressure distribution and ship motion. So, it is necessary to simulate the actual mass distribution. The total mass can be divided into two groups: constant mass and variable mass. The mass, including hull weight, paint weight, hull outfitting weight, machinery weight, electric wires weight and provision weight, is constant regardless of the cargo loading condition. The variable mass, including cargo weight, ballast water weight, fresh water weight, fuel oil weight and diesel oil weight, is different according to individual loading 
condition [12]. In the present research, the maximum static vertical bending moment is taken place at fully loading departure condition so that it is adopted as calculating condition.

The heavy equipments, such as main engine, hatch cover, windlass and so on, are regarded as concentrated mass which shall be represented by the point mass elements distributing in the corresponding area. The mass distribution of light weight except mentioned heavy equipments is divided into 20 segments along ship length which is simulated by correcting the density of element. The variable mass, including cargo, ballast water, fuel oil and so on, is distributed to the corresponding area by modifying the density of element.

Mass distribution tools had been developed based on Patran platform using PCL (Patran Command Language). The density of selected element shall be modified automatically when the actual mass is specified. After the mass distribution, the total mass, position of gravity and inertia moment along $x$-, $y$ - and $z$-axis should be checked to ensure that they are same as the calculating condition.

\subsubsection{Long-Term Prediction of Wave Load}

Long-term prediction refers to determine the extremes beyond the specific probability by statistical method. Long-term wave load can be regarded as a series of $\sqrt{R}\left(R=2 \sigma^{2}\right)$ representing short-term Rayleigh distribution. Therefore, the long-term response distribution of wave induced load and motion can be fitted in accordance with long-term distribution of the probability density function of $\sqrt{R} \quad[13]$.

Long-term prediction of wave load and equivalent design wave height can be obtained according to JONSWAP wave spectrum, wave scatter diagram for E1 navigation area and proposed exceeding probability level using SESAM software. Corresponding ship motion parameters and wave parameters are as follows:

- wave frequency ranges from 0.1 to 2.0 (0.1 interval, total wave frequency number 20);

- angle of waves to ship from $0^{\circ}$ to $180^{\circ}\left(30^{\circ}\right.$ interval, total seven angles);

- zero forward speed and infinite water depth.

Finally, the extreme long-term prediction, the corresponding wave angle, frequency, response of unit wave amplitude and the equivalent design wave height under full loading condition and ballast water condition can be obtained, as shown in Table 3 .

\subsubsection{Load Calculation Result}

The equivalent design wave height can be obtained in previous sub-section. The load calculation can be conducted through the equivalent design wave theory. In this sub-section, the external pressure distribution along ship's hull and corresponding acceleration at the gravity centre under each loading condition are calculated using WADAM solver of SESAM software [14]. WADAM solver is based on widely-accepted linear methods for marine hydrodynamics 3D radiation-diffraction theory employing a panel model. Airy wave theory is applied, and results are presented as complex transfer functions or as deterministic results for specified phases of the wave. The inertial force combining with external pressure shall be treated as external load which will be subjected to entire structural model.

Considering the structural characteristics of objective flat-type river-sea-going container ship, five load cases under full loading condition should be taken into account, namely the maximum vertical bending moment case, the maximum horizontal bending moment case, maximum torsional moment at $\mathrm{L} / 2$ case, maximum torsional moment at $\mathrm{L} / 4$ case and maximum torsional moment at $3 \mathrm{~L} / 4$ case. The load case number and calculation condition are summarized in Table 4.

The external pressure distribution under the maximum vertical bending moment case is shown in Fig. 3. The arrow direction represents the direction of the pressure which is perpendicular to the element surface, and the arrow length represents the magnitude 
Table 3 Long-term prediction of wave load.

\begin{tabular}{llllll}
\hline Loading condition & Angle $\left({ }^{\circ}\right)$ & $\begin{array}{l}\text { Frequency } \\
(\mathrm{rad} / \mathrm{s})\end{array}$ & $\begin{array}{l}\text { Response of unit wave Extreme long-term } \\
\text { height }(\mathrm{N}-\mathrm{m})\end{array}$ & $\begin{array}{l}\text { Equivalent design } \\
\text { prediction }(\mathrm{N}-\mathrm{m})\end{array}$ \\
\hline Full loading condition & 180 & 0.647 & $8.966 \mathrm{e} 7$ & $5.384 \mathrm{e} 8$ & 6.00 \\
Ballast water condition & 180 & 0.688 & $7.698 \mathrm{e} 7$ & $4.612 \mathrm{e} 8$ & 5.99 \\
\hline
\end{tabular}

Table 4 Typical calculation case.

\begin{tabular}{lllll}
\hline LC1 & LC2 & LC3 & LC4 & LC5 \\
\hline $\begin{array}{l}\text { Maximum vertical } \\
\text { bending moment }\end{array}$ & Maximum horizontal & Maximum torsional & Maximum torsional & Maximum torsional \\
bending moment & moment at L/2 & moment at L/4 & moment at 3L/4 \\
\hline
\end{tabular}

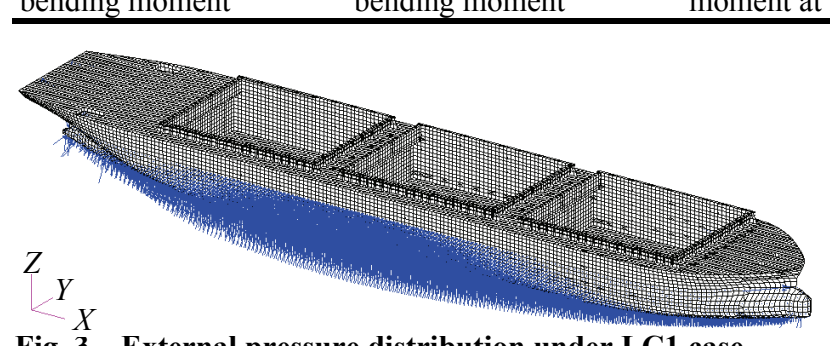

Fig. 3 External pressure distribution under LC1 case.

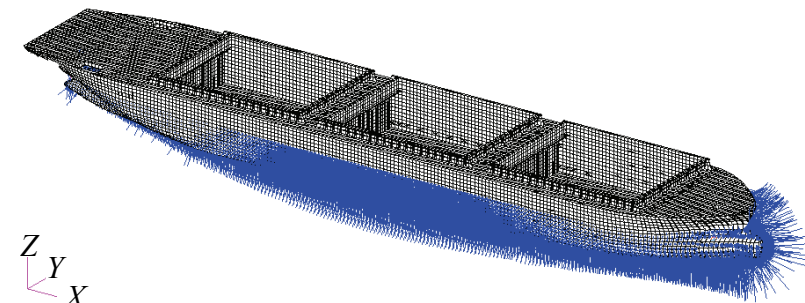

Fig. 4 External pressure distribution under LC4 case.

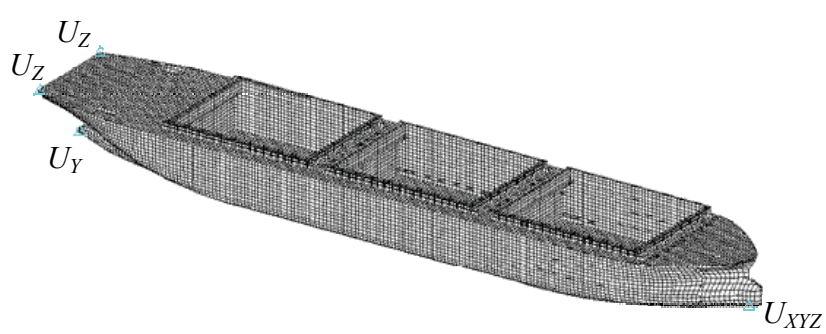

Fig. 5 Entire ship finite element model and boundary condition.

of pressure. The wave crest locates in the middle of ship hull girder so that the pressure is almost zero in the forest end and aft end. The ship hull girder shall be in hogging condition. The pressure distribution under the maximum torsional moment at $\mathrm{L} / 4$ case is demonstrated in Fig. 4. The pressure in starboard side is different from that in port side. In fore part, the pressure in starboard side is larger than that in port side. It is reverse in aft part, which means that pressure in port side is larger. The torsional moment is produced and the maximum one locates at L/4 under the action of mentioned loads.

\section{Structural Direct Calculation}

When the containers loaded to the ship, torsional moment is usually produced due to the different weight of each container. The ship hull is also subjected to both vertical bending and torsional moments when it is in oblique wave. It is necessary to check the structural strength under combined vertical bending and torsional moments in order to ensure the safety of ship structure. Therefore, the finite element model of entire ship is generated and the direct calculated load is applied to it. The strength validation and assessment will be performed for entire ship model under combined bending and torsional moments.

\subsection{Calculation Model and Boundary Condition}

Three-dimensional entire ship model is generated including components of main hull except superstructure. The $x$-axis is the ship length direction and toward the bow is positive. The $y$-axis is breadth direction and toward the port side is positive and $z$-axis upward depth direction. The origin locates at Frame No. 0, central section and baseline. Mesh size is basically frame space or width between longitudinal stiffeners. The plate panel is simulated by shell element and stiffener by beam element. There are 55,646 nodes, 85,440 shell elements and 35,587 beam elements. The entire ship model is shown in Fig. 5.

The navigating ship is freely floating in the sea so that there is no constraint on displacement. Actually, that is no geometrical condition which should be imposed. However, the zero-pivot of global stiffness 
matrix shall appear and the calculation can not be carried out if no displacement is constrained. To avoid this, the minimum constraint is necessary. That is, axial, vertical and horizontal translations are constrained at a nodal point located at the fore end, vertical translation at the top of aft end and horizontal translation at the bottom of the aft end, as shown in Fig. 5.

\subsection{Calculation Condition}

Referring to the guidances for direct analysis of container ship published by Chinese Classification Society [15], six calculation conditions should be considered. The maximum vertical bending moment, the maximum horizontal bending moment, maximum torsional moment at $\mathrm{L} / 2$, maximum torsional moment at $\mathrm{L} / 4$ and maximum torsional moment at 3L/4, combining with static condition, will be calculated in the present research. The relationship between load case and calculation condition is described in Table 5.

\subsection{Structural Direct Calculation Result}

The stress level under static condition is relative low. The maximum stress is only $124 \mathrm{MPa}$ so that there is no problem on yield strength and buckling strength. The corresponding stress distribution is shown in Fig. 6. For other five wave conditions, the maximum Von Mises stress of major components is summarized in Table 6.

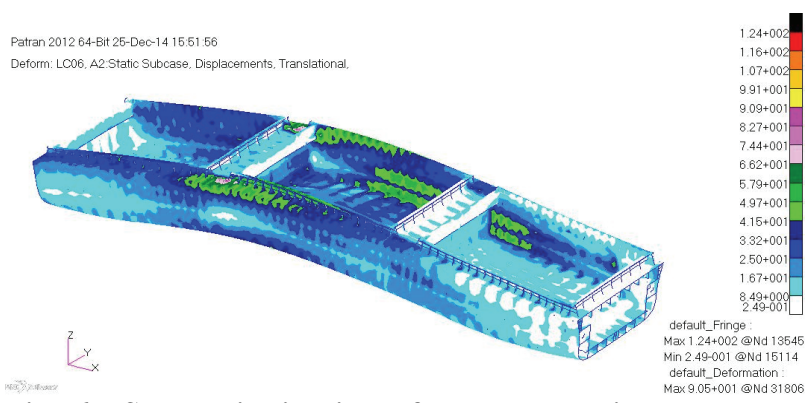

Fig. 6 Stress distribution of components in cargo hold region under static condition.

Table 5 Load case for entire ship model.

\begin{tabular}{llllll}
\hline LC1 & LC2 & LC3 & LC4 & LC5 & LC6 \\
$\begin{array}{l}\text { Maximum vertical } \\
\text { bending moment }\end{array}$ & $\begin{array}{l}\text { Maximum horizontal } \\
\text { bending moment }\end{array}$ & $\begin{array}{l}\text { Maximum torsional } \\
\text { moment at L/2 }\end{array}$ & $\begin{array}{l}\text { Maximum torsional } \\
\text { moment at L/4 }\end{array}$ & $\begin{array}{l}\text { Maximum torsional } \\
\text { moment at 3L/4 }\end{array}$ & Static condition \\
\hline
\end{tabular}

Table 6 Maximum Von Mises stress of major components under wave conditions (units in MPa).

\begin{tabular}{|c|c|c|c|c|c|c|c|c|c|c|}
\hline \multirow{2}{*}{ Load case } & \multirow{2}{*}{$\begin{array}{l}\text { Bottom } \\
\text { plate }\end{array}$} & \multirow{2}{*}{$\begin{array}{l}\text { Inner bottom } \\
\text { plate }\end{array}$} & \multirow{2}{*}{$\begin{array}{l}\text { Bottom } \\
\text { girder }\end{array}$} & \multicolumn{2}{|c|}{ Longitudinal stiffener } & \multirow{2}{*}{$\begin{array}{l}\text { Shell } \\
\text { plate }\end{array}$} & \multirow{2}{*}{$\begin{array}{l}\text { Inner hull } \\
\text { plate }\end{array}$} & \multirow{2}{*}{$\begin{array}{l}\text { Upper } \\
\text { deck plate }\end{array}$} & \multirow{2}{*}{$\begin{array}{l}\text { Hatch } \\
\text { coaming }\end{array}$} & \multirow{2}{*}{$\begin{array}{l}\text { Transverse } \\
\text { bulkhead plate }\end{array}$} \\
\hline & & & & Bottom & Inner bottom & & & & & \\
\hline $\mathrm{LC} 1$ & 142 & 97.5 & 125 & 174 & 22.8 & 203 & 315 & 315 & 315 & 154 \\
\hline LC2 & 125 & 72.1 & 82.2 & 90 & 42.9 & 104 & 133 & 136 & 129 & 88.1 \\
\hline LC3 & 170 & 120 & 121 & 182 & 45.6 & 167 & 241 & 241 & 228 & 118 \\
\hline LC4 & 195 & 133 & 136 & 189 & 53 & 200 & 284 & 284 & 284 & 143 \\
\hline LC5 & 129 & 93 & 97.9 & 152 & 34.3 & 134 & 217 & 217 & 222 & 97.2 \\
\hline
\end{tabular}

Table 7 Minimum buckling factor of major component in various wave conditions.

\begin{tabular}{lcccccc}
\hline Load case & LC1 & LC2 & LC3 & LC4 & LC5 & Buckling or not \\
\hline Deck & 8.71 & 11.80 & 9.74 & 7.38 & 12.40 & No \\
Inner bottom & 1.97 & 2.95 & 1.76 & 1.56 & 2.16 & No \\
Bottom & 1.10 & 2.05 & 1.12 & 1.03 & 1.38 & No \\
Inner hull & 0.93 & 1.59 & 0.93 & 0.87 & 1.22 & Yes \\
Shell & 1.29 & 2.25 & 1.04 & 1.02 & 1.30 & No \\
Transverse bulkhead & 0.96 & 1.83 & 0.97 & 0.80 & 1.45 & Yes \\
Girder & 1.14 & 2.20 & 1.01 & 0.91 & 1.31 & No \\
3,800-platform & 2.83 & 3.88 & 1.59 & 1.56 & 2.04 & No \\
6,300-platform & 8.10 & 8.04 & 5.05 & 3.78 & 8.09 & No \\
\hline
\end{tabular}




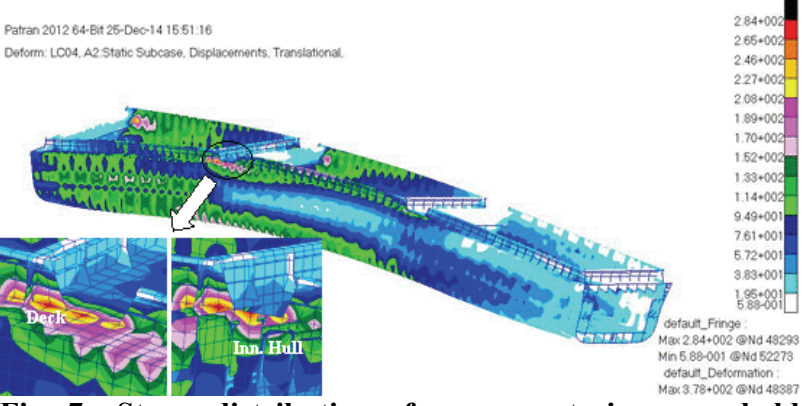

Fig. 7 Stress distribution of components in cargo hold region under LC1 condition.

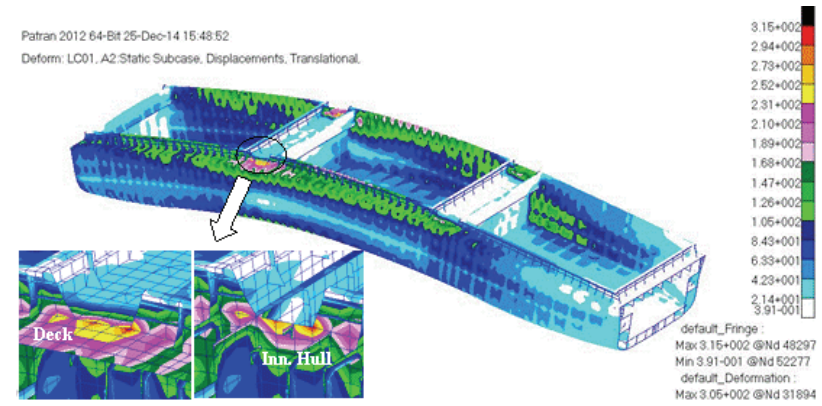

Fig. 8 Stress distribution of components in cargo hold region under LC4 condition.

In the LC1 condition (maximum vertical wave bending moment condition), the maximum stress occurs in the conjunction region among upper deck, inner hull and bracket toe of hatch side coaming between the centre hold and aft hold. This region is subjected to larger vertical bending moment and there is structural discontinuity which leads to high stress. Stress distribution of components in cargo hold region, as well as the maximum stress region, is shown in Fig. 7.

In the LC4 condition (maximum torsional moment at $\mathrm{L} / 4$ condition), the maximum stress is up to $284 \mathrm{MPa}$ in the starboard side between the centre hold and aft hold due to the interaction of vertical bending moment and torsional moment. Stress distribution of hold region and the stress concentration region are demonstrated with deformed mode, as shown in Fig. 8.

\subsection{Structural Strength Assessment}

Referring to guidances for direct analysis of container ship published by Chinese Classification
Society [15], the allowable stress for plating in entire ship model is $190 / k$ MPa while $235 / k$ MPa for local concentration region where $k$ is material factor. For high strength steel with yield stress $355 \mathrm{MPa}, k$ is taken as 0.72 . The material for bottom, upper deck, hatch coaming, top of side shell and top of inner hull adopts high strength steel with yield stress $355 \mathrm{MPa}$ whereas others mild steel (yield stress $235 \mathrm{MPa}$ ). Therefore, the allowable stress for plating of bottom, upper deck, hatch coaming, top of side shell and top of inner hull is $264 \mathrm{MPa}$ while $326 \mathrm{MPa}$ for local concentration region.

The maximum stress in static condition is $124 \mathrm{MPa}$, less than $190 \mathrm{MPa}$.

The maximum stress of bottom, upper deck, hatch coaming, top of side shell and top of inner hull in LC2, LC3 and LC5 conditions is $228 \mathrm{MPa}$, less than allowable stress (264 MPa) for high strength steel plating. Observing from Fig. 7, the maximum stress in LC1 condition is $315 \mathrm{MPa}$, locating in the conjunction area among upper deck, inner hull and hatch coaming which belongs to local stress concentration. There is also local stress concentration in LC4 condition and the maximum stress is $284 \mathrm{MPa}$. As pointing in last section, the allowable stress for high strength steel plating in local stress concentration region is $326 \mathrm{MPa}$.

For the mild steel plating, such as inner bottom, girder, bottom longitudinal stiffener, inner bottom longitudinal stiffener and transverse bulkhead, the maximum stress under all calculation conditions is $189 \mathrm{MPa}$, not larger than allowable stress (190 MPa).

So, the stress of all components is less than allowable stress. They can satisfy the requirements of the structural strength criteria.

\subsection{Evaluation of Plating Buckling Strength}

When the plate panel is subjected to compression thrust or shear, the plate panel shall not keep the equilibrium status any longer, and the lateral deflection is happened in case the compression thrust 
or shear increases to critical load. After performing the structural direct calculation, the load subjected to each plate panel can be obtained. The ratio of structural critical load to subjected load is the so-called buckling factor. If the buckling factor is larger than 1.0, the structural capacity is larger than subjected load so that the plate panel buckling will not be happened. Otherwise, the plate panel shall be buckled when the buckling factor is less than 1.0. The minimum buckling factor of major components and the assessment on buckling strength is shown in Table 7.

From the buckling calculation results, the buckling strength of inner hull plating and transverse bulkhead plating can not be satisfied in LC1 (maximum vertical bending moment), LC3 (maximum torsional moment at $\mathrm{L} / 2$ ) and LC4 (maximum torsional moment at L/4) conditions. To improve the plating buckling strength, there are two possible ways: increasing plate thickness or adding carling in the panel. Increasing plate thickness will lead to increase of structural weight that seems not so good. One carling will be added to the plate panel which the buckling strength is not satisfied. After the reinforcement of one carling, all the buckling factors are larger than 1.0 that satisfies the requirement of buckling strength.

\section{Conclusions}

In the present paper, a flat-type river-sea-going container ship is researched. Its ratio of $\mathrm{B} / \mathrm{D}$ is up to 2.98, exceeding the definition of present rules, which lead to difficulty in structural design. The characteristic of wave load acted on river-sea-going ship is also quite different from that on sea-going ship or inland ship. To ensure the safety of structural design, both load direct calculation and structural direct calculation are performed. The main findings are as follows:

(1) The exceeding probability level is determined according to the actual status of navigation route and operation situation which plays important role on load direct calculation;

(2) The wave spectrum and wave scatter diagram shall reflect the wave characteristics of navigation area that influences the long term prediction of wave load;

(3) Long-term prediction is performed with proper wave spectrum, wave scatter diagram and reasonable exceeding probability level to obtain equivalent design wave height;

(4) Load direct calculation is conducted in accordance with equivalent design wave theory. The external pressure distribution and corresponding inertia force can be obtained;

(5) The direct calculated load is added to entire structural model, and structural direct calculation is performed. The corresponding structural strength is evaluated.

The present research method including load direct calculation and structural direct calculation is feasible to design safe, reasonable and rational structural system for new structural type beyond the definition of existing rules.

\section{Acknowledgments}

The project is sponsored by the Ministry of Industry and Information for High-Tech Ship Technology Project "Development and Application of River-Sea-Going Container Ship with Energy-Saving and Environment-Protecting" and the scientific research foundation for the returned overseas Chinese scholars. The finance support is highly appreciated.

\section{References}

[1] Changjiang River Administration of Affairs. 2014. Report on Changiang River Shipping Development. Beijing: China Communications Press, 168. (in Chinese)

[2] Charlier, J., and Ridilfi, G. 1994. "International Transportation in Europe: Of Modes, Corridors and Nodes." Maritime Policy and Management 21: 12-23.

[3] Fu, H. 2013. "Ultimate Strength Study of River-to-Sea Ships." Master thesis, Wuhan University of Technology.

[4] Faust, P. 1998. "Maritime Transport, Linear Market and Policy Development." Presented at International 
Workshop on Shipping Policies and Development, Shanghai, China.

[5] Zoran, R. 2003. "Sustainable Inland Waterway Transport and European Development Guidelines on Danubean Navigable Network." Cemt.org. Accessed October 30, 2015. http://www.cemt.org/online/Water05/ Radmilovic.pdf.

[6] Qi, W. 2005. "The Present Situation and Future of River-Sea-Going Transportation in China." Traffic and Transportation 5: 20-1.

[7] Li, Y., and Niu, C. 2008. "Technique Status and Future Development of River-Sea-Going Ship." Storage Transportation and Preservation of Commodities 167: 46-7.

[8] China Classification Society. 2012. Rules for Construction of Steel Ship. Beijing: China Communications Press, 525.

[9] Zhang, W., Liu, G., and Wu, W. 2011. "Investigation on the Wave Load for River-Sea Bulk Carriers.” Journal of
Wuhan University of Technology (Transportation Science and Engineering) 35: 752-5.

[10] Dai, Y., Shen, J., and Song, J. 1996. Ship Wave Loads. Beijing: National Defense Industry Press, 216.

[11] Fang, Z. 1996. The Abnormality in the Northwest Pacific Ocean. Beijing: National Defense Industry Press, 448.

[12] Pei, Z., Iijima, K., Fujikubo, M., Tanaka, S., Okazawa, S., and Yao, T. 2015. "Simulation on Progressive Collapse Behaviour of Whole Ship Model under Extreme Waves Using Idealized Structural Unit Method." Marine Structures 40: 104-33.

[13] Liu, H., and Zhang, S. 2013. "Direct Strength Analysis of 3,600-DWT Dry Cargo Ship Based on Design Wave Approach." Ship and Ocean Engineering 42: 33-7.

[14] DNV (Det Nrske Veritas). 2005. WADAM User Manual. Oslo: DNV, 213.

[15] China Classification Society. 2013. Guidances for Direct Analysis of Container Ship. Beijing: China Communications Press, 35. 